\title{
Research on calcifications in the cervical region using panoramic and teleradiographic techniques
}

\author{
Calcificações na região cervical utilizando radiografias panorâmicas e telerradiografias
}

Rosangela Sayuri Saga KAMIKAWA'

Ricardo RAITZ2

Marlene Fenyo PEREIRA ${ }^{1}$

\section{ABSTRACT}

\section{Objective}

The aim of the study was to evaluate the contribution of lateral and frontal teleradiographs to the identification and location of calcifications in soft tissues, when compared with those observed in panoramic radiographs.

\section{Methods}

Radiopaque references in gutta-percha were placed unilaterally on the heads of three cadavers, endeavoring at all times to keep to the same level as the bifurcation of the common carotid artery in different structures, sites of possible calcifications, and three radiographic incidences were obtained for each anatomic part. Thus, the sample of this study was composed of 27 panoramic radiographs, 27 lateral teleradiographs and 27 frontal teleradiographs, totaling 81 radiographs.

\section{Results}

According to the criteria of Cicchetti and Sparrow, the intraclass correlation coefficients (ICCS) obtained were below 0.40.

\section{Conclusion}

It can be concluded that the lateral and frontal teleradiographs did not contribute efficiently to the identification and location of radiopacities in the cervical region, and that the anatomic conformation interferes in the observation of the presence of radiopacity in the cervical region.

Indexing terms: Atherosclerosis. Diagnosis. Radiography.

\section{RESUMO}

Objetivo

Avaliar a contribuição das telerradiografias, nas normas lateral e frontal, na identificação e localização de calcificações em tecidos moles, quando comparado com as observadas em radiografia panorâmica.

\section{Métodos}

Referências opacas em guta percha foram posicionadas unilateralmente, em três cabeças de cadáveres, procurando manter sempre no mesmo nível da bifurcação da artéria carótida comum, em diferentes estruturas, sítios de possíveis calcificações e foram obtidas três incidências radiográficas para cada peça anatômica. Assim, a amostra deste estudo foi composta por 27 radiografias panorâmicas, 27 telerradiografias em norma lateral e 27 telerradiografias em norma frontal, totalizando 81 radiografias.

\section{Resultados}

De acordo com os critérios de Cicchetti e Sparrow observou-se valores inferiores a 0,40 de coeficiente de correlação intraclasse (CCI) entre os métodos.

\section{Conclusão}

Foi possível concluir que as telerradiografias em norma lateral e frontal não contribuem eficazmente na identificação e localização de radiopacidades na região cervical, e que a conformação anatômica interfere na observação da presença de radiopacidade na região cervical.

Termos de indexação: Arteriosclerose. Diagnóstico. Radiografia.

\footnotetext{
${ }^{1}$ Universidade de São Paulo, Faculdade de Odontologia, Departamento de Estomatologia. Av. Prof. Lineu Prestes, 2227, Cidade Universitária, 05508000, São Paulo, SP, Brasil. Correspondência parta / Correspondence to: MF PEREIRA. E-mail: <mfenyo@usp.br>.

${ }^{2}$ Faculdade São Leopoldo Mandic, Curso de Odontologia, Programa de Pós-Graduação em Odontologia. Campinas, SP, Brasil.
} 


\section{INTRODUCTION}

Panoramic radiography is the most used extra-oral radiographic exam in dentistry, providing a broad vision of the dental-buccal-maxillary-facial complex. When present, calcifications in soft tissues can be observed by means of this exam, but it is necessary to know the principles of interpretation in these radiographs, in order to identify these calcifications in the head and neck regions. The literature has warned about the presence of radiopaque images in panoramic radiographs, adjacent to the spine, indicative of calcifications in the bifurcation of the carotid artery, representing signs of the presence of atheromas, which my degenerate into more serious cerebrovascular and cardiac diseases ${ }^{1-3}$.

Different radiopaque images can be observed in the cervical region (anatomic and pathologic), whose characteristics should be known.

There are, however, considerations to be made with regard to the different physical constitutions between sexes, races, and even related to the physical type of the individual, which may produce differentiated projections in panoramic radiographs.

Historically, dentists have used lateral cephalometric radiographs to evaluate the facial morphologic characteristics of children and adolescents in the stage of growth; that is, persons with low risk of developing atherosclerosis. Recently, however, dentists have used this image modality to evaluate adult patients that sought orthodontic treatment, implants and sleep apnea therapy. The prevalence of atherosclerosis in the carotid artery among these patients is undoubtedly greater, therefore becomes advantageous for dentists to pay attention to observing calcified atheromas in cephalometric radiographs. Many dentists could help in the prevention of certain diseases, especially those who treat a large number of patients over the age of 40 years, and those who use this exam for some type of dental evaluation ${ }^{4}$.

In panoramic radiographs, there are still doubts about the exact location of these calcifications in soft tissues, which may lead to errors in interpretation, so that it is justifiable to conduct this study using lateral and frontal teleradiographs as complementary radiographic images for diagnosis.

\section{METHODS}

The research project was evaluated and approved by the Research Ethics Commission of the Pontifical Catholic University of Parana, Curitiba, State of Parana, Brazil, and the Research Ethics Commission of the Dental Faculty of University of São Paulo, Brazil was informed about it.

The sample of this study was composed of 27 panoramic radiographs, 27 lateral teleradiographs and 27 frontal teleradiographs, totaling 81 radiographs, obtained from three anatomic parts of cadavers, conserved in formol, consisting of the head and neck, belonging to the Anatomy Department of the Pontifical Catholic University of Parana, Curitiba, and State of Parana, Brazil.

To simulate calcifications in soft tissues in the anatomic parts, round shaped radiopaque references $(\mathrm{Rr})$ were made of gutta-percha on a sharp pointed rod made from polystyrene (Figure 1).These references were placed unilaterally, at all times seeking the same level of the common carotid artery bifurcation, in the following structures and locations:

- Submandibular gland: in the inferior third of the superficial face of the superficial portion of the submandibular gland, in the anterior-posterior and superior-inferior direction.

- Thyroid cartilage: on the superior horn.

- Triticeous cartilage: on the triticeous cartilage.

- Bifurcation of the common carotid artery: inside the bifurcation.

- Hyoid Bone: greater horn of the hyoid bone.

- Stylohyoid Ligament: close to the insertion of the stylohyoid ligaments on the greater horn of the hyoid bone.

- Stylomandibular ligament: close to the insertion of the stylomandibular ligament on the angle of the mandible.

- Palatine Tonsil: in the central region.

- Epiglottis: on the apex.

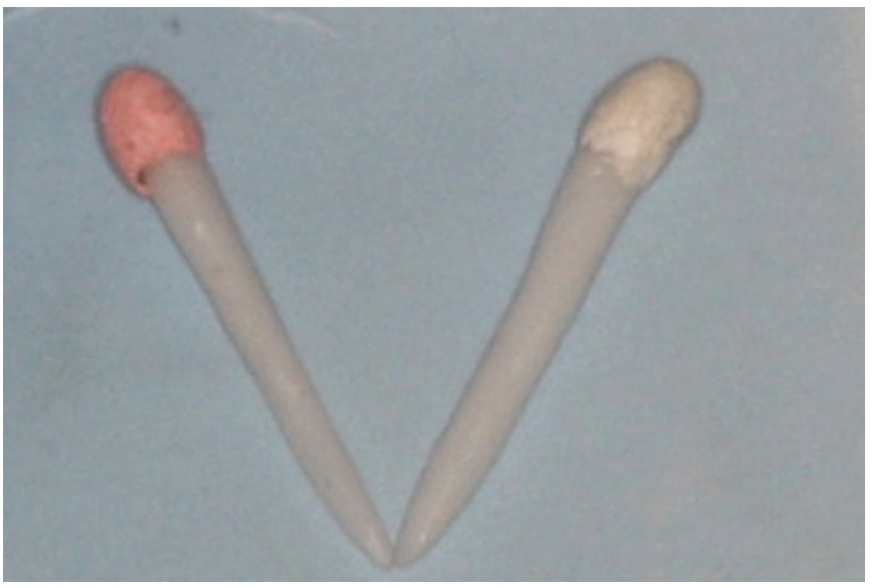

Figure 1. Radiopaque references in gutta-percha.

For each of the above-mentioned structures, a panoramic radiograph, a lateral teleradiograph and a frontal teleradiograph were obtained, thus totaling three incident radiographic images for each anatomic piece. 
To obtain the radiographs, the panoramic appliance Orthophos CD (Siemens Corp ${ }^{\circledR}$, Munich, Bavaria,
Germany) was used. The working regime established is shown in Table 1:

Table 1. Working regimes use for performing different techniques on different heads.

\begin{tabular}{|c|c|c|c|c|c|c|c|c|c|}
\hline & \multirow{2}{*}{$k V p$} & \multicolumn{2}{|c|}{ Panoramic } & \multicolumn{3}{|c|}{ Lateral telerradiograph } & \multicolumn{3}{|c|}{ Frontal telerradiograph } \\
\hline & & $\mathrm{mA}$ & seconds & kVp & $\mathrm{mA}$ & seconds & kVp & $\mathrm{mA}$ & seconds \\
\hline Head 1 & 60 & 14 & 14 & 84 & 13 & 0,25 & 84 & 13 & 0,25 \\
\hline Head 2 & 60 & 10 & 14 & 84 & 13 & 0,25 & 84 & 13 & 0,32 \\
\hline Head 3 & 60 & 14 & 14 & 84 & 13 & 0,25 & 84 & 13 & 0,25 \\
\hline
\end{tabular}

The radiographic films used were T-Mat G/RA (Kodak ${ }^{\circledR}$, Rochester, N.Y. USA), size $15 \times 30 \mathrm{~cm}$, with Lanex intensifying screen (medium), size $15 \times 30 \mathrm{~cm}$ (Kodak ${ }^{\circledR}$, Rochester, N.Y. USA) for taking the panoramic radiograph. To take the lateral and frontal teleradiographs, T-Mat G/RA $\left(\right.$ Kodak $^{\circledR}$, Rochester, N.Y. USA), size $18 \times 24 \mathrm{~cm}$ films, with Lanex intensifying screen (medium), size $18 \times 24 \mathrm{~cm}$ (Kodak ${ }^{\circledR}$, Rochester, N.Y. USA) were used. All the radiographs were processed automatically with a Glunz \& Jensen- Electronic and Mechanical Engineering ${ }^{\circledR}$ processor, Model Multi-X 36 (Glunz \& Jensen Inc. ${ }^{\circledR}$, Copenhagen, Denmark) with Kodak ${ }^{\circledR}$ brand processing solutions.

To standardize the positioning of the anatomic part and stabilize it on the panoramic appliance, a mannequin bust made from polypropylene (Legas Metal ${ }^{\circledR}$, São Paulo, S.P, Brazil) was used.

Each anatomic part was therefore, placed in the panoramic appliance on the mannequin bust, following the habitual orientations for positioning patients.

The radiographs were evaluated by 5 dental radiologists with a minimum of 5 years' professional experience. Evaluations were made in a room with subdued ambient light with standart viewing box, without the use of magnifying lenses. They were asked to evaluate the 81 radiographs, and answer two questions:

1 Using the lateral and frontal teleradiographs and panoramic radiographs, check which was the most probable location of the radiopaque reference. Identify with letters of the alphabet using the options provided below.

a) Stylohyoid ligament

b) Carotid artery bifurcation

c) Superior horn of the thyroid cartilage

d) Epiglottis

e) Stylomandibular ligament

f) Submandibular gland

g) Triticeous cartilage

h) Greater horn of the hyoid bone

i) Palatine tonsil

2 In your opinion, in the cases presented, when observing the radiopaque images in the locations suggestive of calcifications in soft tissues in the panoramic radiograph, and lateral and frontal teleradiographs, do they help in the differential diagnosis of these calcifications? Answer S (yes) or N (no).

\section{Statistical analysis}

The data collected on the examiners' observations were analyzed for the intraclass correlation coefficient for more than 2 examiners, with the use of the "on line" statistical package of the University of Hong Kong (2009).

\section{RESULTS}

With regard to the first question, an intraclass analysis of correct answers among five examiners was made. The results the observations are shown in Table 2 .

Table 2. Frequency of correct answers by examiners in evaluating the anatomic structures in the heads of cadavers.

\begin{tabular}{|c|c|c|}
\hline Head & Anatomic structure & Correct answers \% \\
\hline \multirow{9}{*}{1} & 3 & 60 \\
\hline & 7 & 40 \\
\hline & 8 & 40 \\
\hline & 9 & 40 \\
\hline & 1 & 0 \\
\hline & 2 & 0 \\
\hline & 4 & 0 \\
\hline & 5 & 0 \\
\hline & 6 & 0 \\
\hline \multirow{9}{*}{2} & 4 & 60 \\
\hline & 9 & 60 \\
\hline & 1 & 40 \\
\hline & 7 & 40 \\
\hline & 8 & 40 \\
\hline & 3 & 20 \\
\hline & 6 & 20 \\
\hline & 2 & 0 \\
\hline & 5 & 0 \\
\hline \multirow{9}{*}{3} & 3 & 80 \\
\hline & 9 & 80 \\
\hline & 5 & 60 \\
\hline & 1 & 40 \\
\hline & 7 & 40 \\
\hline & 8 & 40 \\
\hline & 4 & 20 \\
\hline & 6 & 20 \\
\hline & 2 & 0 \\
\hline
\end{tabular}

Note: Anatomic structures: 1 - Submandibular gland; 2 - superior horn of the thyroid cartilage; 3 - triticeous cartilage; 4 - carotid artery bifurcation; 5 - greater horn of the hyoid bone; 6 - stylohyoid ligament; 7 stylomandibular ligament; 8 - palatine tonsil; 9 - epiglottis. 


\section{Head 1}

The $(\mathrm{Rr})$ that was located on the triticeous cartilage received the highest percentage of correct answers (60\%) by the examiners. Followed by $40 \%$ for the reference located on the stylomandibular ligament, palatine tonsil and epiglottis. There were no correct answers for the following structures: submandibular gland, superior horn of the thyroid cartilage,carotid artery bifurcation, greater horn of the hyoid bone and stylohyoid ligament.

\section{Head 2}

The examiners obtained $60 \%$ of correct answers in the radiographs in which the $(\mathrm{Rr})$ were situated in the bifurcation of the carotid artery and epiglottis, $40 \%$ in the submandibular gland, stylomandibular ligament and palatine tonsil, $20 \%$ in the triticeous cartilage and stylohyoid ligament. There were no correct answers for the following structures: superior horn of the thyroid cartilage and greater horn of the hyoid bone.

\section{Head 3}

The $(\mathrm{Rr})$ that were located on the triticeous cartilage and epiglottis obtained the highest percentage of correct answers (80\%) by the examiners; on the greater horn of the hyoid bone $(60 \%) ; 40 \%$ on the submandibular gland, stylomandibular ligament and palatine tonsil; $20 \%$ in the bifurcation of the carotid artery and stylohyoid ligament. There were no correct answers in the radiographs in which the (Rr) were on the superior horn of the thyroid cartilage.

Table 3 refers to the intraclass correlation coefficients (ICC) obtained using the "on line" statistical package of the University of Hong Kong (2008), which were: 0.0977 for all the results; 0.0075 for head $1 ; 0.0645$ for head 2; 0.0977 for head 3. According to the criteria of Cicchetti and Sparrow ${ }^{5}$ the ICC can be classified for the levels of clinical significance, as: poor < 0,40; reasonable, 0.40 to 0.59 ; good, 0.60 to 0.74 ; excellent, $0, .75$ to 1.00 . All the ICCs obtained were below 0.40 .

Table 3. Intraclass Correlation Coefficient in evaluating the anatomic structures of the heads of cadavers.

\begin{tabular}{cc}
\hline Exams & ICC $^{*}$ \\
\hline Total & 0.0977 \\
Head 1 & 0.0075 \\
Head 2 & 0.0645 \\
Head 3 & 0.0977 \\
\hline
\end{tabular}

Note: ICC - Intraclass Correlation Coefficient. * Absence of correlation among the observers.

With regard to the second question, $95.55 \%$ of affirmative answers were obtained by the examiners as regards the help of lateral and frontal teleradiographs in the differential diagnosis of calcifications when the radiopaque images were observed in the locations suggestive of calcifications in soft tissues in the panoramic radiograph.

\section{DISCUSSION}

The observation of radiopaque images adjacent to the cervical regions in panoramic radiographs has been of considerable interest over the last few years, particularly with regard to the presence of calcifications in the carotid artery region. The clinician must distinguish calcified atheromas of the carotid artery from anatomic and pathologic radiopacities present in these proximities. The anatomic radiopacities include the hyoid bone, epiglottis, and stylomandibular and stylohyoid ligaments. The pathologic radiopacities that may present in the carotid artery region include the calcified thyroid cartilage, more precisely the superior horn, calcification in the submandibular gland, phleboliths, calcified lymph nodes and tonsilloliths. Based on the location and typical morphology of the above-mentioned entities, there is rarely any problem with distinguishing them from calcified atheromas ${ }^{1}$. The purpose of this research work was to help in the identification of these variabilities and draw attention to the existence of these structures, thereby reducing the possibility of these being diagnosed as calcified atheromas of the carotid. To do this, ( $R r)$ were distributed by inserting them in the structures in which the highest number of mistaken identifications was believed to occur, and after this panoramic radiographs and lateral and frontal teleradiographs of the heads of cadavers were obtained. The $(\mathrm{Rr})$ were inserted on the anatomic structures on purpose, at the same level of the carotid artery bifurcation. After obtaining the images, they were submitted to 05 dental radiologists with a minimum experience of 5 years, so that they would mark which would be most probable location of the calcification, or the anatomic structure, in the 81 radiographs handed to them.

Many practitioners do not know that a calcified triticeous cartilage could be confused with a calcified atheroma1. However, the results of the present study pointed out that the $(\mathrm{Rr})$ that was located on the triticeous cartilage obtained the highest percentage of correct answers (60\%) by the examiners in head $01 ; 20 \%$ in head 02 and $80 \%$ in head 03 (Figures 2, $3,4)$. Since the study of Friedlander and Lande3, in 
which they determined the presence and frequency of the occurrence of atherosclerotic plaques in panoramic radiographs, these observations gave rise to a certain trend among professionals, so that every and any calcification observed close to this region in panoramic radiographs would be pointed out as atheromas of the carotid $^{6}$. Nevertheless, over the last few years, studies conducted by authors ${ }^{7-10}$ have been used as references with respect to calcifications of the triticeous cartilage and furthermore, the most recent studies ${ }^{11-12}$, emphasizing the importance of this anatomic structure with regard to diagnosis of the location of the radiopacity.

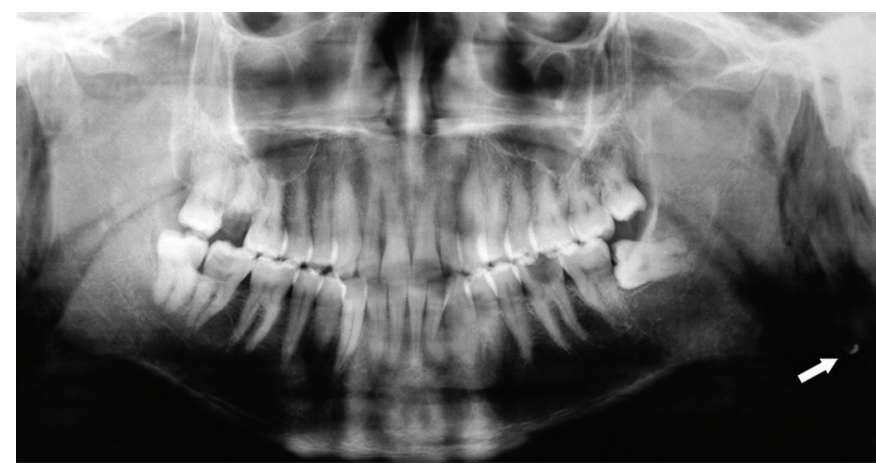

Figure 2. Panoramic radiograph of head 3 with radiopaque reference on triticeous cartilage (arrow)

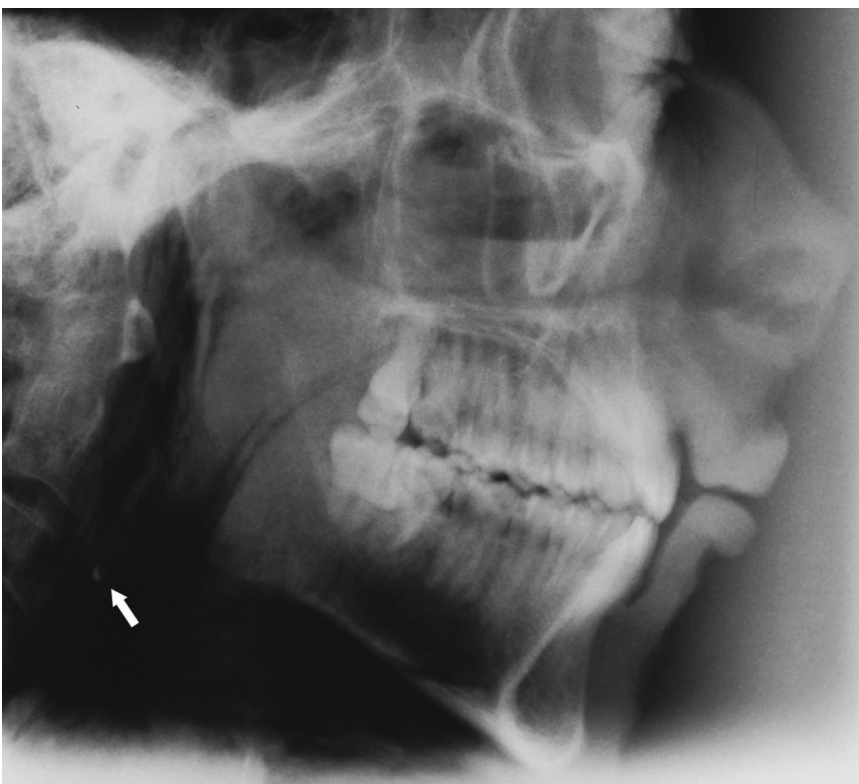

Figure 3. Head 3-Lateral telerradiograph of head 3 with radiopaque reference on triticeous cartilage (arrow).

The results of the present study also point out correct answers with regard to the epiglottis ( $40 \%$ in heads $01 ; 02$ and 03 ) and the palatine tonsil (40\% in head 01 ; $60 \%$ in head 02 and $80 \%$ in head 03). The use of frontal teleradiographs helped in diagnosis, since such structures are located more centrally (Figure 5).

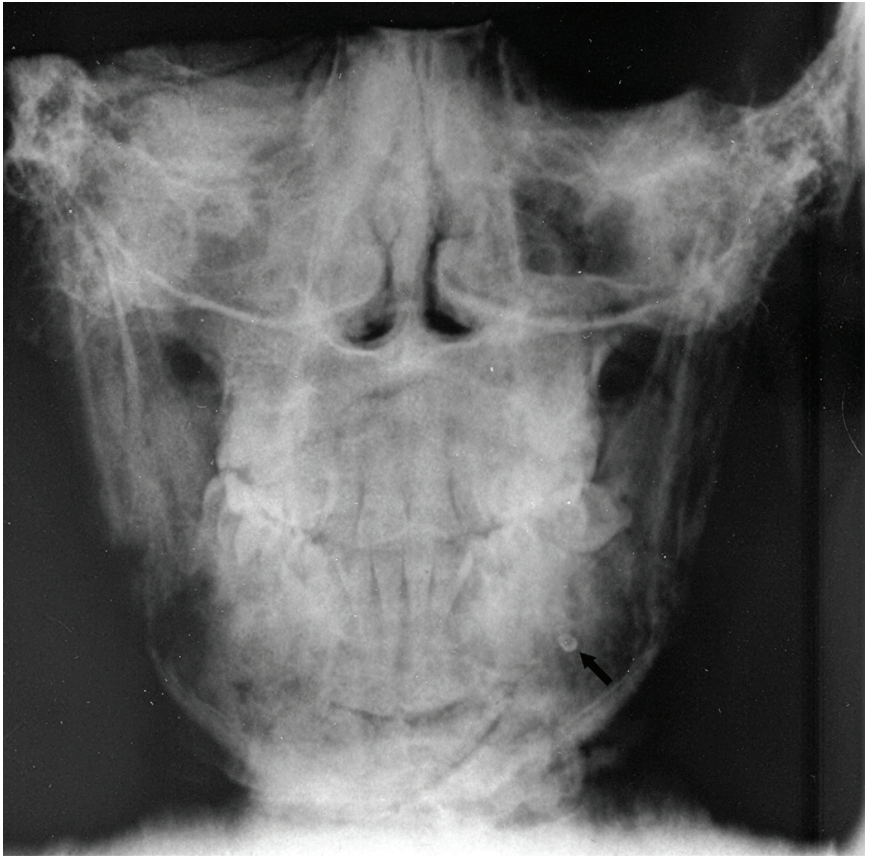

Figure 4. Head 3-Frontal telerradiograph of head 3 with radiopaque reference on triticeous cartilage (arrow).

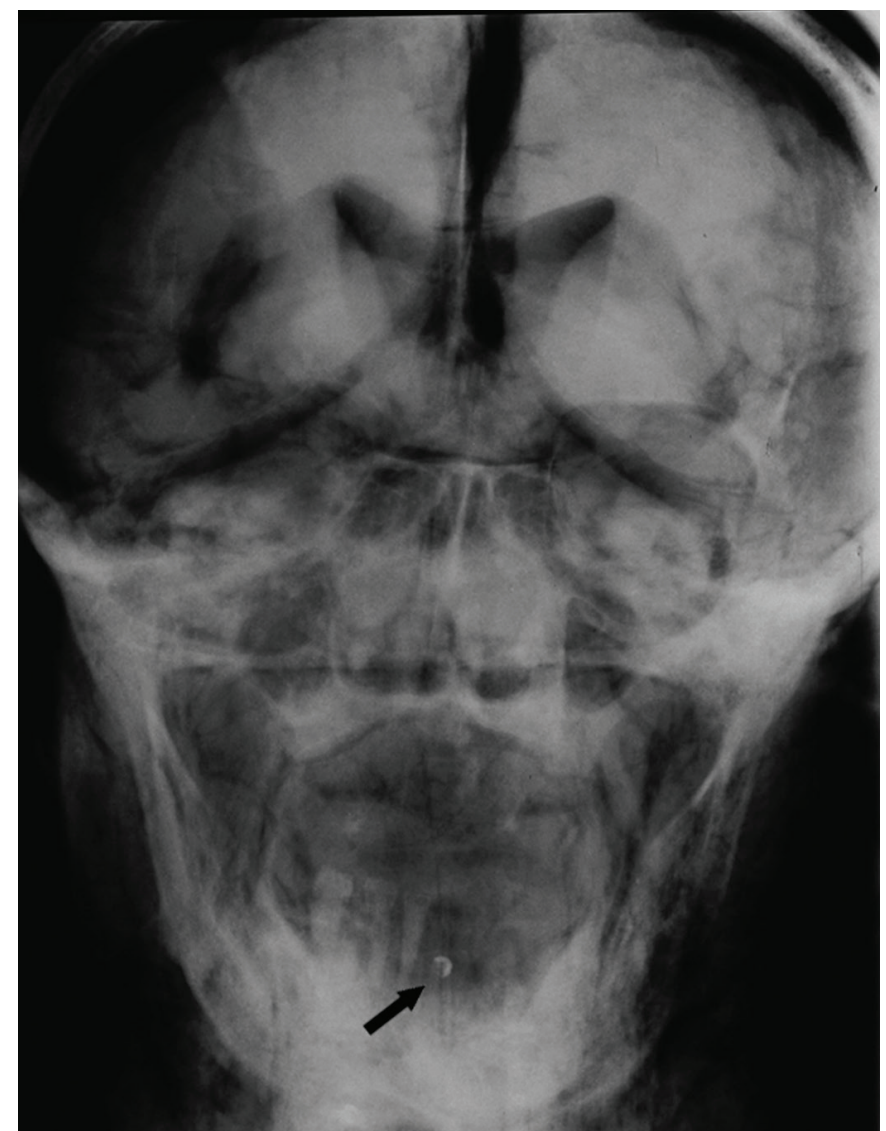

Figure 5. Head 1 - Frontal telerradiograph of head 1 with radiopaque reference on epiglottis (arrow) 
The results obtained in the present study corroborate those observed by Carter ${ }^{1}$ that the calcifications of the superior horn of the thyroid cartilage are frequently unknown by dentists, as in general, only the superior portion ( 2 to $3 \mathrm{~mm}$ ) of this calcified cartilage is visible at the inferior edge of the panoramic radiograph. Only if the film were positioned beyond the inferior limit, would a longer view of this cartilage be seen. In the present research there were no correct answers when the radiopaque reference was located on the superior horn of the thyroid cartilage.

Until a short time ago, only children and adolescents were submitted to orthodontic treatments using cephalometric radiographs. There are reports of the calcified thyroid cartilage image and its ossification being observed by means of cephalometric radiography ${ }^{13-14}$, but the ossification of this cartilage does not occur before the second decade of life. With the growing demand by adult patients in the age bracket from 20 to 60 years of age for orthodontic treatment, it is believed that calcification of the superior horn of the thyroid cartilage, when it occurs, could be noted more frequently and easily by dentists.

In the study conducted to determine whether calcified lesions could be detected by means of conventional lateral cephalometric radiographs, it was concluded that such radiographs could demonstrate calcifications consistent with atherosclerosis of the carotid artery ${ }^{4}$. The same result was not obtained in the present study, since the mean of correct answers by the examiners was not constant with regard to the radiopaque reference located in the region of the carotid artery bifurcation. In head 1 there were no correct answers; in head 2 there were $60 \%$ of correct answers and 20\% for head 3. This probably occurred, as it is known that calcifications in the carotid artery may appear as a nodular radiopaque mass, or as two vertical radiopaque lines within the walls of the artery, at the level of the inferior margin of the third cervical vertebra ${ }^{15}$ or even adjacent, but not contiguous to the third and fourth cervical vertebrae. However, in head 01 the bifurcation was at the level of the second cervical vertebra (C2), which is very rare. In the study conducted by Klosek and Rungruang ${ }^{16}$ the majority of carotid bifurcations were found at the level of $\mathrm{C} 3$, between $\mathrm{C} 3$ and $\mathrm{C} 4$, and vertebra C4, and a trend

\section{REFERENCES}

1. Carter LC. Discrimination between calcified triticeous cartilage and calcified carotid atheroma on panoramic radiography. Oral towards the more inferior position in men was also noted. In this study, the larger portion of carotid bifurcations were found at the level of vertebrae C3 and C4, but two cases of high carotid bifurcation at the level of vertebrae $\mathrm{C} 2$ and C3 were noted unilaterally, corresponding to $2.7 \%$ of all the carotid bifurcations, which could be explained by the embryology of the internal carotid artery from the second aortic $\operatorname{arch}^{17}$. The incidence of this variation is rare, around $1 \%{ }^{18}$. In the studies of Anu et al..$^{19}$ the carotid bifurcation was found at the level of C2 in 10\% of cases and only in $1 \%$ was it at the level of $C 5$.

With regard to the second question, even the percentage of affirmative answers of $95.55 \%$ by the examiners about the help of lateral and frontal teleradiographs with differential diagnosis of calcifications, the correct answers corresponded to intraclass correlation coefficients (ICC) below 0.40 . The ICC could be classified for the clinical level of significance as poor $<0.40^{5}$.

The few correct answers related to head 1 occurred due to the anatomic variation of this specimen, thus confirming that in different biotypes, there are doubts about the location of calcification. Moreover, the difficulty of answering correctly about the insertion of ( $\mathrm{Rr}$ ) can be justified, because they were always positioned seeking the same level of the carotid artery bifurcation.

\section{CONCLUSION}

The normal and frontal teleradiographs did not contribute effectively to the identification and location of radiopacities in the cervical region. The anatomic conformation interferes in the observation of the presence of radiopacity in the cervical region.

\section{Collaborators}

RSS KAMIKAWA, R RAITZ and M FENYO-PEREIRA guided all stages of research from conception and methodology of the study, data collection, data analysis and writing the paper. All authors reviewed the paper and approved its final version.
Surg Oral Med Oral Pathol Oral Radiol Endod. 2000;90(1):10810. doi: 10.1067/moe.2000.106297

2. Friedlander $\mathrm{AH}$. Identification of stroke-prone patients by panoramic and cervical spine radiography. Dentomaxillofac Radiol. 1995;24(3):160-4. 
3. Friedlander $\mathrm{AH}$, Lande $\mathrm{A}$. Panoramic radiographic identification of carotid arterial plaques. Oral Surg Oral Med Oral Pathol. 1981;52(1):102-4. doi: 10.1016/0030-4220(81)90181-X

4. Friedlander $A H$, Dounis $G$, Gratt BM. Lateral cephalometric radiographs: an aid in detecting patients at risk of stroke. J Am Dent Assoc. 1996;127(12):1745-50. doi: 10.14219/jada. archive.1996.0135

5. CicchettI DV, Sparrow SS. Developing criteria for establishing interrater reliability of specific items: applications to assessment of adaptive behavior. Am J Ment Defic. 1981;86(2):127-37.

6. Kamikawa RS, Pereira MF, Fernandes A, Meurer MI. Study of the localization of radiopacities similar to calcified carotid atheroma by means of panoramic radiography. Oral Surg Oral Med Oral Pathol Oral Radiol Endod. 2006;101(3):374-8. doi: 10.1016/j.tripleo.2005.03.030

7. Ajmani ML. A metrical study of the laryngeal skeleton in adult Nigerians. J Anat. 1990;171:187-91.

8. Ajmani ML, Jain SP, Saxena SK. A metrical study of laryngeal cartilages and their ossification. Anat Anz. 1980;48(1):42-8.

9. Hately W, Evison G, Samuel E. The pattern of ossification in the laryngeal cartilages: a radiological study. Brit J Radiol. 1965;38:585-91. doi: 10.1259/0007-1285-38-452-585

10. O'Bannon RP, Grunow $\mathrm{OH}$. The larynx and pharynx radiologically considered. South Med J. 1954;47(4):310-6.

11. Ahmad M, Madden R, Perez L. Triticeous cartilage: prevalence on panoramic radiographs and diagnostic criteria. Oral Surg Oral Med Oral Pathol Oral Radiol Endod. 2005;99(2):225-30. doi: 10.1016/j.tripleo.2004.06.069

12. Ahmad M, Madden R, El-Ashiry K. Prevalence of carotid calcified atherosclerotic plaques on panoramic radiographs. J Dent Res. 2002;82(Special Issue A):3990.
13. Mupparapu M, Vuppalapati A. Detection of an early ossification of thyroid cartilage in an adolescent on a lateral cephalometric radiograph. Angle Orthod. 2002;72(6):576578. doi: 10.1043/0003-3219(2002)072<0576:DOAEOO>2.0 $\mathrm{CO} ; 2$

14. Salman RA, Kinney LA. Calcified thyroid cartilage. Oral Surg Oral Med Oral Pathol. 1990;70(6):806-7.

15. Friedlander $\mathrm{AH}$, Friedlander IK. Identification of stroke prone patients by panoramic radiography. Aust Dent J. 1998;43(1):514. doi: 10.1111/j.1834-7819.1998.tb00153.x

16. Klosek SK, Rungruang T. Topography of carotid bifurcation: considerations for neck examination. Surg Radiol Anat. 2008;30(5):383-7. doi: 10.1007/s00276-008-0337-2

17. Sadler TW. Langman's medical embryology. 6th ed. Baltimore: Williams and Wilkins; 1990

18. Gluncic V, Petanjek Z, Marusic A, Gluncic I. High bifurcation of common carotid artery, anomalous origin of ascending pharyngeal artery and anomalous branching pattern of external carotid artery. Surg Radiol Anat. 2001;23(2):123-5. doi: $10.1007 / \mathrm{s} 00276-001-0123-x$

19. Anu VR, Pai MM, Rajalakshmi $R$, Latha VP, Rajanigandha $V$, D'Costa S. Clinically-relevant variations of the carotid arterial system. Singapore Med J. 2007;48(6):566-9.

Received on: 15/4/2016

Final version resubmitted on:17/5/2016

Approved on: 11/6/2016 